\title{
Palladium-Templated Subcomponent Self-Assembly of Macrocycles, Catenanes, and Rotaxanes**
}

\author{
Colm Browne, Tanya K. Ronson, and Jonathan R. Nitschke*
}

\begin{abstract}
The reaction of 2,6-diformylpyridine with diverse amines and $P d^{I I}$ ions gave rise to a variety of metallosupramolecular species, in which the Pd ${ }^{I I}$ ion is observed to template a tridentate bis(imino)pyridine ligand. These species included a mononuclear complex as well as [2+2] and [3+3] macrocycles. The addition of pyridine-containing macrocyclic capping ligands allows for topological complexity to arise, thereby enabling the straightforward preparation of structures that include a [2]catenane, a [2]rotaxane, and a doubly threaded [3]rotaxane.
\end{abstract}

$T_{\text {he preparative method of subcomponent self-assembly has }}$ proven effective for the high-yielding, one-pot synthesis of complex architectures from simple starting materials. ${ }^{[1]}$ By allowing amines and aldehydes to condense around a metal template, a variety of metallosupramolecular structures, such as capsules ${ }^{[2]}$ and interlocked assemblies, ${ }^{[3]}$ have been synthesized, with applications including anion binding ${ }^{[4]}$ and molecular magnetism. ${ }^{[5]}$ This has been made possible through the use of metal-ion templates including octahedral $\mathrm{Fe}^{\mathrm{II}}{ }^{[6]} \mathrm{Ni}^{\mathrm{II}}{ }^{[7]}$ $\mathrm{Co}^{\mathrm{II}},{ }^{\mathrm{I}]} \mathrm{Zn}^{\mathrm{II}}$, ${ }^{[\mathrm{h}]}$ and $\mathrm{Cd}^{\mathrm{II}}$ ions, ${ }^{[9]}$ as well as tetrahedral $\mathrm{Cu}^{\mathrm{I}[10]}$ ions and higher-coordinate lanthanides. ${ }^{[5]}$ Square-planar $\mathrm{Pd}^{\mathrm{II}}$ ions have not yet been used for subcomponent self-assembly, although $\mathrm{Pd}^{\mathrm{II}}$ has proven very useful in the synthesis of complex supramolecular architectures. ${ }^{[11]}$ We envisaged that the use of $\mathrm{Pd}^{\mathrm{II}}$ ions with pyridylimine ligands could provide access to new architectures, unattainable using other metalion templates.

Metal-ion templates have been combined with amines and 2,6-diformylpyridine in the synthesis of a variety of complex supramolecular structures, including Stoddart's Borromean links and Leigh's catenanes, ${ }^{[12]}$ and although such structures with $\mathrm{Pd}^{\mathrm{II}}$ ions are unknown, mononuclear complexes with related tridentate ligands have been reported. ${ }^{[13]}$ Herein we outline the preparation of a range of supramolecular archi-

[*] C. Browne, Dr. T. K. Ronson, Prof. J. R. Nitschke University of Cambridge, Department of Chemistry Lensfield Road, Cambridge, CB2 1EW (UK)

E-mail: jrn34@cam.ac.uk

Homepage: http://www-jrn.ch.cam.ac.uk/

[**: This work was underwritten by the Marie Curie Academic-Industrial Initial Training Network on Dynamic Molecular Nanostructures (DYNAMOL) of the European Union's Seventh Framework Programme (FP7) and the UK Engineering and Physical Sciences Research Council (EPSRC). We thank the Cambridge Chemistry NMR service for experimental assistance, Diamond Light Source (UK) for synchrotron beamtime on 119 (MT7984), and the EPSRC National Crystallography Service for X-ray data collection. Supporting information for this article is available on the WWW under http://dx.doi.org/10.1002/anie.201406164. tectures through the subcomponent self-assembly of $\mathrm{Pd}^{\mathrm{II}}$ ions and 2,6-diformylpyridine with a variety of amines, and their modification through the addition of monodentate ligands to create interlocked structures.

We hypothesized that mixing an amine with 2,6-diformylpyridine and a $\mathrm{Pd}^{\mathrm{II}}$ salt would lead to their condensation to form a ligand system suitable for the synthesis of metallosupramolecular assemblies. The amine and dialdehyde moieties would thus react to form a tridentate ligand occupying three coordination sites of the metal ion, with the fourth being taken up by a solvent molecule or counter anion. This ligand system offers three advantages: 1) its dynamic imine bonds allow for the straightforward introduction of new functionality through variation of the identity of the amine added; 2) $\mathrm{Pd}^{\mathrm{II}}$ ions are capable of acting as electrostatic anchors in host-guest systems; ${ }^{[14]}$ and 3 ) the acetonitrile bound to the palladium ion can be displaced by a stronger donor, such as a pyridyl-based ligand, to generate heteroleptic structures.

The simple mononuclear complex 1 (Figure 1) was first prepared to test the viability of our hypothesis. The reaction of $p$-anisidine and $\left[\mathrm{Pd}(\mathrm{MeCN})_{4}\right]\left(\mathrm{BF}_{4}\right)_{2}$ with 2,6-diformylpyridine in a 2:1:1 ratio led to the formation of a deep-red solution within seconds. The choice of $p$-anisidine was due to its high nucleophilicity and consequent stabilizing effect in the formation of imine bonds. ${ }^{[15]}$ The ${ }^{1} \mathrm{H}$ NMR spectrum of 1 (Figure 1) shows significant coordination-induced shifts of the aromatic signals ${ }^{[16]}$ and confirmed quantitative formation of the imine-based ligand through the appearance of a singlet at $8.22 \mathrm{ppm}$. ESI-MS also confirmed the formation of $\mathbf{1}$.

Following the successful synthesis of $\mathbf{1}$, further reactions were investigated to create new architectures. We hypothesized that the use of diamines instead of simpler monoamines would lead to multinuclear complexes. The combination of 4,4'-oxydianiline with $\left[\mathrm{Pd}(\mathrm{MeCN})_{4}\right]\left(\mathrm{BF}_{4}\right)_{2}$ and 2,6-diformylpyridine in a 1:1:1 ratio led to the rapid formation of an intensely red solution (Scheme 1 ). The ${ }^{1} \mathrm{H}$ NMR spectrum (see Figure S2 in the Supporting Information) again showed signals consistent with the rapid formation of a single highly symmetrical product. Mass spectrometry was unable to provide insight into the product structure because of fragmentation, even under conditions where the parent ions of other sensitive and highly charged structures had been observed. ${ }^{[17]} \mathrm{X}$-ray quality crystals were grown by slow diffusion of diethyl ether into an acetonitrile solution. Single-crystal X-ray diffraction experiments revealed the structure formed to be the [3+3] macrocycle 2 (Figure 2).

The crystal structure reveals each $\mathrm{Pd}^{\mathrm{II}}$ center to be bound to a pyridine nitrogen and two imine nitrogen atoms, with an acetonitrile ligand occupying the final coordination site. The 


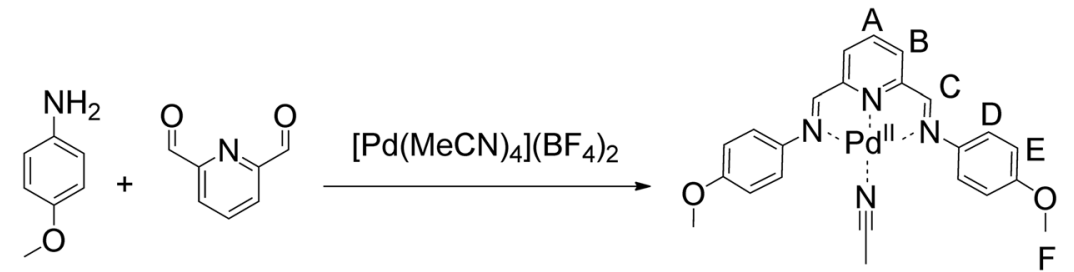

1

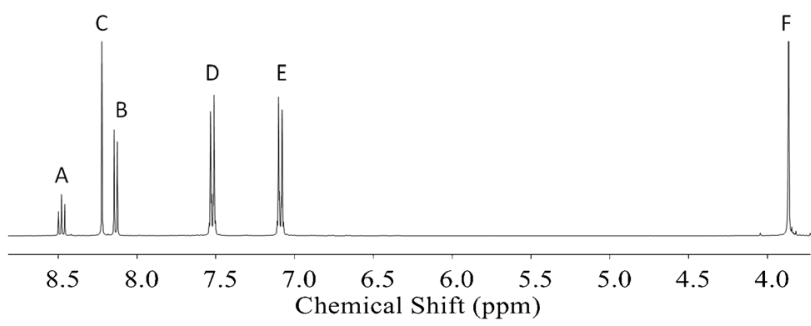

Figure 1. Synthesis and ${ }^{1} \mathrm{H}$ NMR spectrum of 1.

square-planar coordination geometry shows distortion (average $\mathrm{N}_{\text {imine }}-\mathrm{Pd}-\mathrm{N}_{\text {pyridyl }}$ angle $80.9^{\circ}$ ) as a result of the tridentate coordination geometry of the ligand. The three $\mathrm{Pd}^{\mathrm{II}}$ centers bound within the macrocyclic cavity are separated by an average distance of $11.4 \AA$. The bis(phenyl) ether bond angle present in $4,4^{\prime}$-oxydianiline (average $118.9^{\circ}$ ) leads the macro- cycle to adopt a bowl-like shape with a shallow cavity, folding in such a way that all the pyridine groups fall on the same side of the plane defined by the three $\mathrm{Pd}^{\mathrm{II}}$ centers and alleviating steric clash between the acetonitrile ligands. In the solid state, two macrocyclic complexes come together to encapsulate three tetrafluoroborate anions between the $\mathrm{Pd}^{\mathrm{II}}$ centers, thereby resulting in average $\mathrm{Pd}-\mathrm{Pd}$ distances of $6.6 \AA$ between adjacent macrocycles.

We postulated that macrocycles of different sizes and shapes could be synthesized through changing the geometry of the diamine used. To prepare a macrocycle with a moredefined cavity we selected bis(3-aminophenyl)sulfone as a diamine subcomponent. The functionalization of the diphenylsulfone backbone at the 3- and 3'-positions (rather than at 4 and $4^{\prime}$ ) reduces the angle between the two amine C-N vectors. This arrangement would increase the strain of a $[3+3]$ macrocycle such as $\mathbf{2}$, likely leading to the preferred formation of a $[2+2]$ macrocycle. The mixing of bis(3-aminophenyl)sulfone, $\left[\mathrm{Pd}(\mathrm{MeCN})_{4}\right]\left(\mathrm{BF}_{4}\right)_{2}$, and 2,6-diformylpyridine in acetonitrile in a 1:1:1 ratio led to the formation of a dark yellow homogeneous solution, the ${ }^{1} \mathrm{H}$ NMR spectrum of which reflected the formation of

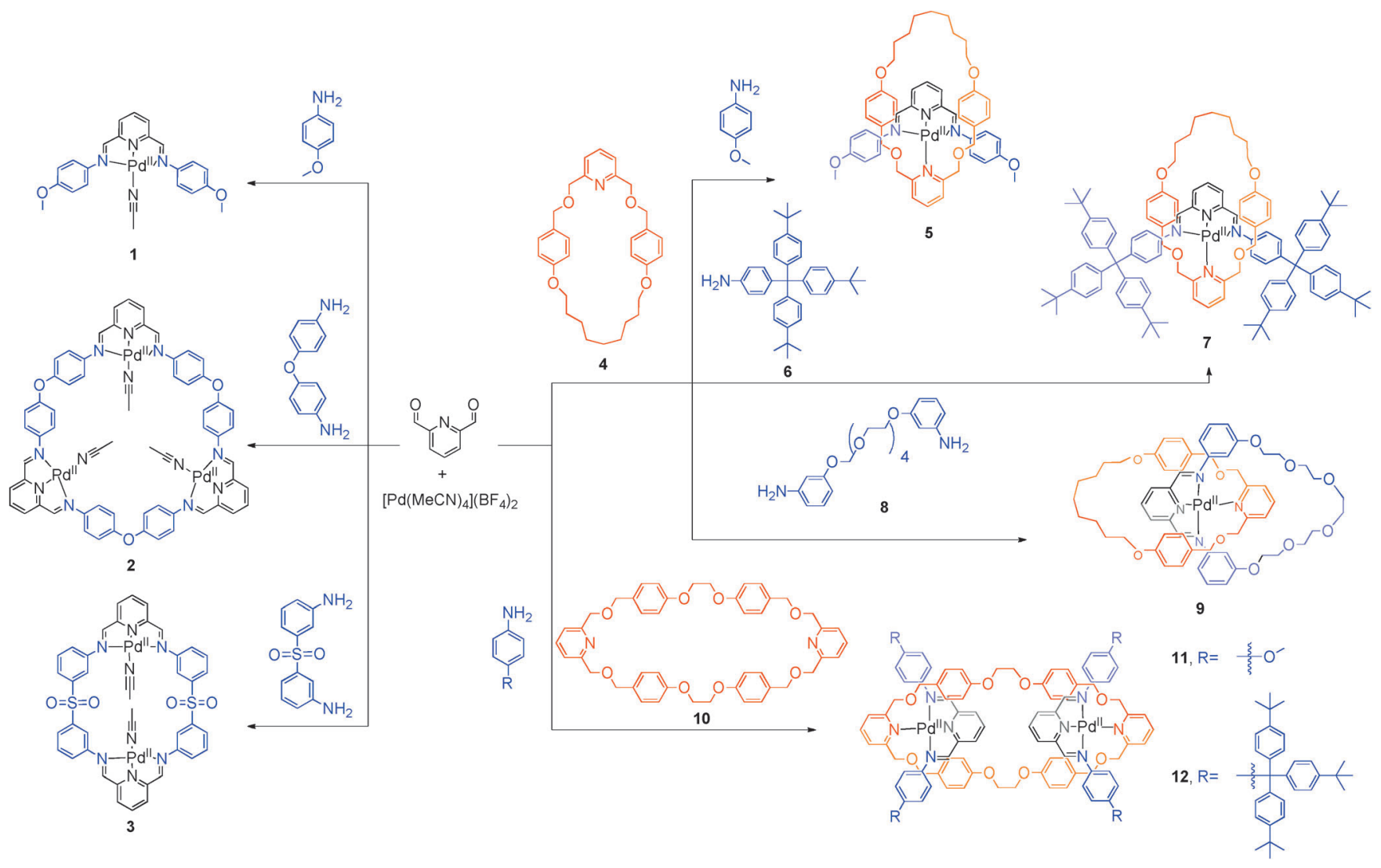

Scheme 1. Synthesis of a range of metallosupramolecular architectures from 2,6-diformylpyridine, Pd" ions, different mono- and diamines, and ancillary ligands. 


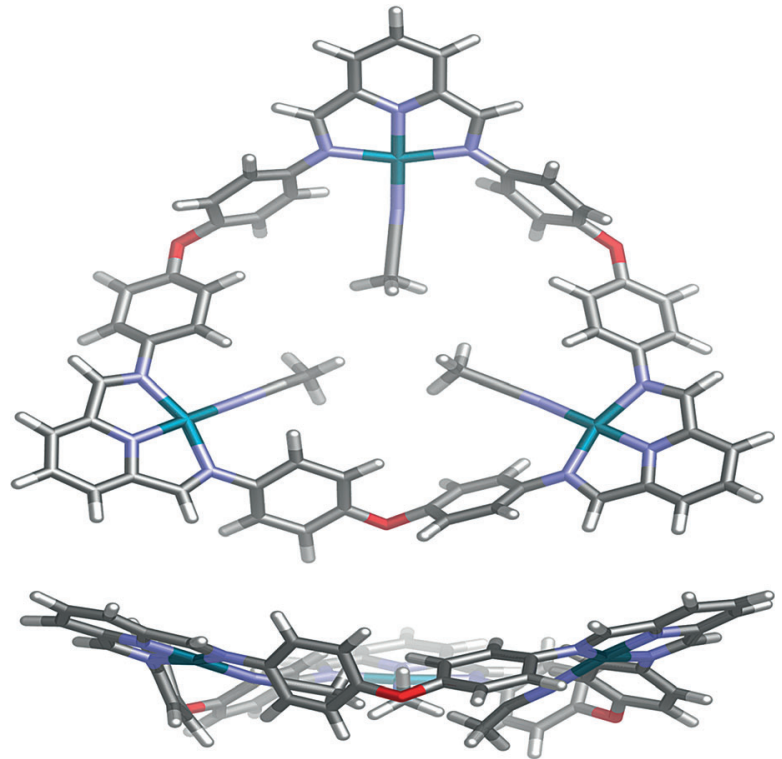

Figure 2. Two views of the crystal structure of 2 . Counterions, solvent, and disorder are omitted for clarity ( $\mathrm{C}$ : gray, $\mathrm{N}$ : light blue, $\mathrm{O}$ : red, $\mathrm{Pd}$ : dark blue, $\mathrm{H}$ : white).

a single, symmetrical product after heating the solution at $50^{\circ} \mathrm{C}$ for $12 \mathrm{~h}$ (see Figure S3 in the Supporting Information). Slow diffusion of diethyl ether into this solution led to the formation of yellow crystals. Single-crystal X-ray diffraction showed 3 to be the predicted [2+2] macrocycle (Figure 3 ).
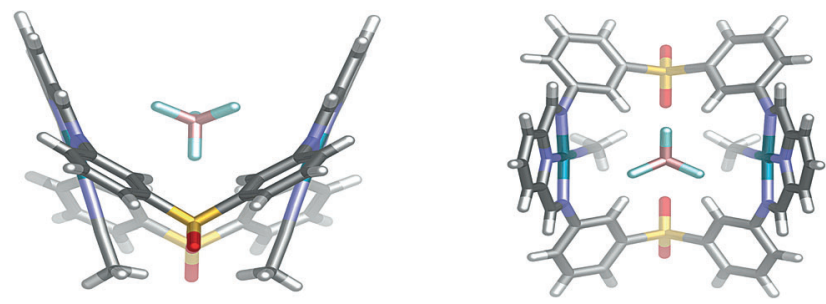

Figure 3. Two views of the crystal structure of $\mathbf{3}$ showing a tetrafluoroborate anion bound within its cavity. Free counterions, solvent, and disorder are omitted for clarity (C: gray, $\mathrm{N}$ : blue, S: yellow, O: red, B: pink, $\mathrm{F}$ : turqouise, $\mathrm{Pd}$ : dark blue, $\mathrm{H}$ : white).

The coordination environments around the $\mathrm{Pd}^{\mathrm{II}}$ centers of $\mathbf{3}$ are similar to those observed in $\mathbf{2}$. To avoid steric clashes between the imine protons and the diphenylsulfone backbone, the pyridine rings are observed to adopt a configuration in which they have rotated out of coplanarity with the phenyl rings. This configuration also alleviates any steric clash between the acetonitrile ligands. The $\mathrm{C}-\mathrm{SO}_{2}-\mathrm{C}$ bond angles of the sulfones are $108.5(3)^{\circ}$ and $105.1(3)^{\circ}$, with the mean planes of the two pyridine rings lying at an angle of $36.4^{\circ}$ to each other. The distance between the $\mathrm{Pd}^{\mathrm{II}}$ centers is 6.7694(6) $\AA$, thereby providing a positively charged cleft. The solid-state structure reveals a $\mathrm{BF}_{4}^{-}$ion within this cavity, sandwiched between the two $\mathrm{Pd}^{\mathrm{II}}$ centers. Tetrafluoroborate was also observed to bind within $\mathbf{3}$ in fast exchange on the
NMR time scale in solution: the ${ }^{19} \mathrm{~F} \mathrm{NMR}$ spectrum of $\mathbf{3}$ in acetonitrile solution revealed the chemical shift of the anion to be shifted upfield by nearly one ppm compared to tetramethylammonium tetrafluoroborate in acetonitrile solution, which is comparable to shifts seen for the binding of this anion in other metal-organic hosts. ${ }^{[18]}$

Interlocked molecular architectures have attracted substantial attention, with catenanes and rotaxanes showing potential in such fields as molecular motors, ${ }^{[19]}$ information storage, ${ }^{[20]}$ and porous materials. ${ }^{[21]}$ The preparation of topologically complex architectures often requires lengthy organic syntheses, which subcomponent self-assembly could shorten. The Leigh research group has shown $\mathrm{Pd}^{\mathrm{II}}$ ions to be a suitable template for the synthesis of catenanes and rotaxanes, wherein the $\mathrm{Pd}^{\mathrm{II}}$ ion and a preformed tridentate ligand define a plane through which an orthogonal, auxiliary ligand is threaded. ${ }^{[22]}$ By using similar principles we postulated that the formation of $\mathbf{1}$ in the presence of pyridine-based macrocycle 4 would lead to the formation a new complex, pseudorotaxane 5 (Scheme 1).

Several factors render $\mathbf{4}$ a suitable ligand for generating interlocked systems with this $\mathrm{Pd}^{\mathrm{II}}$-based system. The phenyl rings of the macrocycle are optimally spaced to $\pi$-stack with the aromatic backbone of a pseudorotaxane, and the pyridyl moiety is a suitable ligand to displace the coordinated acetonitrile molecule in $\mathbf{1}$ to form a new heteroleptic structure. Indeed, mixing the subcomponents in acetonitrile and heating to $60^{\circ} \mathrm{C}$ led to formation of an orange product. Its ${ }^{1} \mathrm{H}$ NMR spectrum reflected the clean formation of a single, symmetrical species, which was shown by DOSY NMR experiments to possess a larger hydrodynamic radius than $\mathbf{1}$. ESI mass spectrometry also confirmed our formulation of $\mathbf{5}$. Its threaded topology was reflected in NOESY NMR correlations between protons that would only be in proximity in a pseudorotaxane (see Figure S10 in the Supporting Information).

The true rotaxane $\mathbf{7}$, in which the axle and macrocycle are linked by a mechanical bond, ${ }^{[23]}$ could be synthesized by employing the bulky amine $\mathbf{6}$ in place of $p$-anisidine (Scheme 1). This rotaxane also formed rapidly as the uniquely observed product, and its presence in solution was confirmed by NMR spectroscopy and mass spectrometry experiments (see Figures S14-S16 in the Supporting Information).

As discussed above, the use of diamines can lead to the formation of macrocyclic metal complexes 2 and 3. These cycles have openings that are too small to accommodate the threading of macrocycles necessary for conversion into a catenane, or axles to generate a rotaxane. However, mixing the flexible diamine $\mathbf{8}$ with 2,6-diformylpyridine, $\left[\mathrm{Pd}(\mathrm{MeCN})_{4}\right]\left(\mathrm{BF}_{4}\right)_{2}$, and 4 followed by heating at $50^{\circ} \mathrm{C}$ for $24 \mathrm{~h}$ in acetonitrile led to the formation of [2]catenane $\mathbf{9}$, as confirmed by ESI-MS (see Figure S19 in the Supporting Information) and ${ }^{1} \mathrm{H}$ NMR spectroscopy (see Figure S6). DOSY (see Figure S18 in the Supporting Information) and NOESY NMR (see Figure S17) experiments provided further evidence for the structure and topology of catenane 9. This topology resulted from $\mathrm{Pd}^{\mathrm{II}}$-templated $[1+1]$ macrocycle formation, along with ligation of $\mathbf{4}$ to the fourth coordination site on the $\mathrm{Pd}^{\mathrm{II}}$ ion (Scheme 1). 
Few examples exist of rotaxanes having more than one axle threaded through a single macrocycle,${ }^{[24]}$ which highlights the greater synthetic challenges posed as topological complexity increases. The principles discussed so far allow for the straightforward design of a system of subcomponents that would self-assemble into a doubly threaded rotaxane structure. Mixing the macrocyclic ligand 10, which bears two pyridine moieties, with the subcomponents of $\mathbf{1}$ led to doubly threaded [3]pseudorotaxane $\mathbf{1 1}$ as the uniquely observed product (Scheme 1). The crystal structure of $\mathbf{1 1}^{[25]}$ (Figure 4)

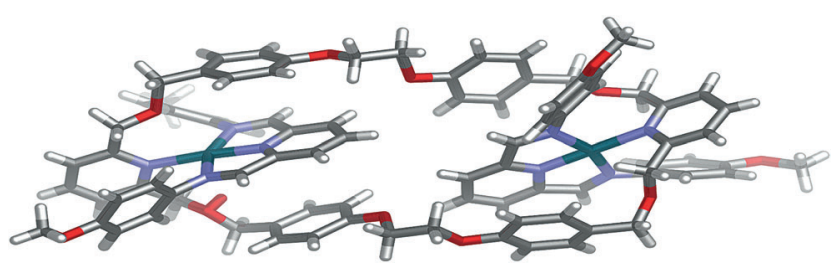

Figure 4. Crystal structure of pseudorotaxane 11. Counterions, solvent, and disorder are omitted for clarity (C: gray, $\mathrm{N}$ : light blue, $\mathrm{O}$ : red, $\mathrm{Pd}$ : dark blue, $\mathrm{H}$ : white). Only one of the two crystallographically unique molecules of 11 is shown. ${ }^{[27]}$

confirmed that the pyridine rings of $\mathbf{1 0}$ had displaced the acetonitrile molecules as expected, and showed how the phenyl rings of $\mathbf{1 0} \pi$-stack with the pyridyl backbone of the threaded molecule. Evidence for the threaded topology of $\mathbf{1 1}$ in solution was provided by $2 \mathrm{D}{ }^{1} \mathrm{H}$ NOE experiments, which showed proximity between the residues of $\mathbf{1 0}$ and the imine protons of the axles (see Figure S20 in the Supporting Information). To the best of our knowledge, compound $\mathbf{1 0}$ is the first example of a pseudorotaxane consisting of two threads through a single macrocycle synthesized either using a square-planar metal template or using dynamic covalent chemistry.

The doubly threaded true rotaxane $\mathbf{1 2}$ could be formed following the same procedure used for the assembly of pseudorotaxane 11, with the mechanical bond between the axle and loop being generated through replacement of anisidine with the much bulkier analogue 6 (Scheme 1). Although no crystal structure could be obtained for 12, its structure is confirmed by mass spectrometry and NMR experiments (see Figures S24 and S25 in the Supporting Information). MM2 molecular modeling assisted in visualizing the structure of the rotaxane, and showed that there is sufficient room for the stopper groups to participate in the same stabilizing $\pi$-stacking interactions as $\mathbf{1 1}$, without steric clashes with the framework of the structure (see Figure S26 in the Supporting Information).

In conclusion, a new $\mathrm{Pd}^{\mathrm{II}}$-bis(imino)pyridine motif has been developed and used to prepare a range of complex metallosupramolecular structures through simple self-assembly processes. Further work aims to elaborate the potential of this motif, through the construction of more intricate and functional structures that employ more than one metal ion to generate structural complexity. ${ }^{[26]}$

Received: June 12, 2014

Published online: August 19, 2014
Keywords: catenanes - host-guest systems - rotaxanes . self-assembly $\cdot$ template synthesis

[1] a) J. Dömer, J. C. Slootweg, F. Hupka, K. Lammertsma, F. E. Hahn, Angew. Chem. 2010, 122, 6575-6578; Angew. Chem. Int. Ed. 2010, 49, 6430-6433; b) A. E. Kaifer, S. Yi, V. Brega, B. Captain, Chem. Commun. 2012, 48, 10295 -10297; c) Y. Wu, X.P. Zhou, J.-R. Yang, D. Li, Chem. Commun. 2013, 49, $3413-$ 3415; d) X.-P. Zhou, Y. Wu, D. Li, J. Am. Chem. Soc. 2013, 135, $16062-16065$; e) X. Wu, N. Xu, Z. Zhu, Y. Cai, Y. Zhao, D. Wang, Polym. Chem. 2014, 5, 1202-1209; f) T. K. Ronson, S. Zarra, S. P. Black, J. R. Nitschke, Chem. Commun. 2013, 49, $2476-2490$.

[2] X.-P. Zhou, J. Liu, S.-Z. Zhan, J.-R. Yang, D. Li, K.-M. Ng, R. W.Y. Sun, C.-M. Che, J. Am. Chem. Soc. 2012, 134, 8042-8045.

[3] S. P. Black, A. R. Stefankiewicz, M. M. J. Smulders, D. Sattler, C. A. Schalley, J. R. Nitschke, J. K. M. Sanders, Angew. Chem. 2013, 125, 5861-5864; Angew. Chem. Int. Ed. 2013, 52, 57495752.

[4] S. Yi, V. Brega, B. Captain, A. E. Kaifer, Chem. Commun. 2012, 48, $10295-10297$.

[5] V. E. Campbell, R. Guillot, E. Riviere, P.-T. Brun, W. Wernsdorfer, T. Mallah, Inorg. Chem. 2013, 52, 5194-5200.

[6] M. C. Young, A. M. Johnson, R. J. Hooley, Chem. Commun. 2014, $50,1378-1380$

[7] H. Bunzen, Nonappa, E. Kalenius, S. Hietala, E. Kolehmainen, Chem. Eur. J. 2013, 19, $12978-12981$.

[8] I. A. Riddell, M. M. J. Smulders, J. K. Clegg, Y. R. Hristova, B. Breiner, J. D. Thoburn, J. R. Nitschke, Nat. Chem. 2012, 4, 751 756.

[9] K.-C. Sham, S.-M. Yiu, H.-L. Kwong, Inorg. Chem. 2013, 52, $5648-5650$.

[10] W. Meng, J. K. Clegg, J. R. Nitschke, Angew. Chem. 2012, 124, 1917-1920; Angew. Chem. Int. Ed. 2012, 51, 1881-1884.

[11] a) Q.-F. Sun, S. Sato, M. Fujita, Nat. Chem. 2012, 4, 330-333; b) Y.-R. Zheng, W.-J. Lan, M. Wang, T. R. Cook, P. J. Stang, J. Am. Chem. Soc. 2011, 133, 17045-17055; c) C. Klein, C. Gütz, M. Bogner, F. Topić, K. Rissanen, A. Lützen, Angew. Chem. 2014, 126, 3814-3817; Angew. Chem. Int. Ed. 2014, 53, 37393742; d) M. Frank, J. Hey, I. Balcioglu, Y.-S. Chen, D. Stalke, T. Suenobu, S. Fukuzumi, H. Frauendorf, G. H. Clever, Angew. Chem. 2013, 125, 10288-10293; Angew. Chem. Int. Ed. 2013, 52, 10102-10106; e) N. Kishi, Z. Li, K. Yoza, M. Akita, M. Yoshizawa, J. Am. Chem. Soc. 2011, 133, 11438-11441; f) A. M. Johnson, O. Moshe, A. S. Gamboa, B. W. Langloss, J. F. K. Limtiaco, C. K. Larive, R. J. Hooley, Inorg. Chem. 2011, 50, 9430-9442; g) R. Sekiya, M. Fukuda, R. Kuroda, J. Am. Chem. Soc. 2012, 134, 10987-10997.

[12] a) L. Hogg, D. A. Leigh, P. J. Lusby, A. Morelli, S. Parsons, J. K. Y. Wong, Angew. Chem. 2004, 116, 1238-1241; Angew. Chem. Int. Ed. 2004, 43, 1218-1221; b) K. S. Chichak, S. J. Cantrill, A. R. Pease, S.-H. Chiu, G. W. V. Cave, J. L. Atwood, J. F. Stoddart, Science 2004, 304, 1308-1312.

[13] a) A. Lavery, S. M. Nelson, J. Chem. Soc. Dalton 1984, 615-620; b) P. Liu, L. Zhou, X. Li, R. He, J. Organomet. Chem. 2009, 694, 2290-2294; c) R. E. Rülke, V. E. Kaasjager, D. Kliphuis, C. J. Elsevier, P. W. N. M. van Leeuwen, K. Vrieze, K. Goubitz, Organometallics 1996, 15, 668-677.

[14] G. H. Clever, S. Tashiro, M. Shionoya, Angew. Chem. 2009, 121, 7144-7146; Angew. Chem. Int. Ed. 2009, 48, 7010-7012.

[15] a) Y. R. Hristova, M. M. J. Smulders, J. K. Clegg, B. Breiner, J. R. Nitschke, Chem. Sci. 2011, 2, 638-641; b) J. R. Nitschke, Acc. Chem. Res. 2007, 40, 103-112.

[16] C. Browne, S. Brenet, J. K. Clegg, J. R. Nitschke, Angew. Chem. 2013, 125, 1998-2002; Angew. Chem. Int. Ed. 2013, 52, 19441948. 
[17] a) I. A. Riddell, Y. R. Hristova, J. K. Clegg, C. S. Wood, B. Breiner, J. R. Nitschke, J. Am. Chem. Soc. 2013, 135, 2723 -2733; b) I. A. Riddell, T. K. Ronson, J. K. Clegg, C. S. Wood, R. A. Bilbeisi, J. R. Nitschke, J. Am. Chem. Soc. 2014, 136, 9491-9498.

[18] S. Ma, M. M. J. Smulders, Y. R. Hristova, J. K. Clegg, T. K. Ronson, S. Zarra, J. R. Nitschke, J. Am. Chem. Soc. 2013, 135, $5678-5684$.

[19] B. K. Juluri, A. S. Kumar, Y. Liu, T. Ye, Y.-W. Yang, A. H. Flood, L. Fang, J. F. Stoddart, P. S. Weiss, T. J. Huang, ACS Nano 2009, 3, 291-300

[20] C. P. Collier, E. W. Wong, M. Belohradský, F. M. Raymo, J. F. Stoddart, P. J. Kuekes, R. S. Williams, J. R. Heath, Science 1999 285, 391-394.

[21] V. N. Vukotic, K. J. Harris, K. Zhu, R. W. Schurko, S. J. Loeb, Nat. Chem. 2012, 4, 456-460.

[22] a) A.-M. L. Fuller, D. A. Leigh, P. J. Lusby, A. M. Z. Slawin, D. B. Walker, J. Am. Chem. Soc. 2005, 127, 12612-12619; b) A. M. Fuller, D. A. Leigh, P. J. Lusby, I. D. H. Oswald, S. Parsons,
D. B. Walker, Angew. Chem. 2004, 116, 4004-4008; Angew. Chem. Int. Ed. 2004, 43, 3914-3918.

[23] J. F. Stoddart, Chem. Soc. Rev. 2009, 38, 1802-1820.

[24] a) A. I. Prikhod'ko, J.-P. Sauvage, J. Am. Chem. Soc. 2009, 131, 6794-6807; b) H. M. Cheng, D. A. Leigh, F. Maffei, P. R. McGonigal, A. M. Z. Slawin, J. Wu, J. Am. Chem. Soc. 2011, 133, 12298-12303; c) S. M. Goldup, D. A. Leigh, P. R. McGonigal, V. E. Ronaldson, A. M. Z. Slawin, J. Am. Chem. Soc. 2010, 132, 315-320; d) C.-F. Lee, D. A. Leigh, R. G. Pritchard, D. Schultz, S. J. Teat, G. A. Timco, R. E. P. Winpenny, Nature 2009, 458, 314-318.

[25] S. J. Coles, P. A. Gale, Chem. Sci. 2012, 3, 683-689.

[26] a) H.-B. Wu, Q.-M. Wang, Angew. Chem. 2009, 121, 7479-7481; Angew. Chem. Int. Ed. 2009, 48, 7343-7345; b) S. Hiraoka, Y. Sakata, M. Shionoya, J. Am. Chem. Soc. 2008, 130, 10058-10059.

[27] CCDC 1007701 (3), 1007702 (2), and 1007703 (11) contain the supplementary crystallographic data for this paper. These data can be obtained free of charge from The Cambridge Crystallographic Data Centre via www.ccdc.cam.ac.uk/data_request/cif. 